\title{
Phase Characterization of Re-Based Diffusion Barrier Layer on Nb Substrate
}

\author{
Eni Sugiarti ${ }^{1,2, *}$, Youngmin Wang ${ }^{1}$, Naoyuki Hashimoto ${ }^{1}$, Somei Ohnuki ${ }^{1}$ and Toshio Narita ${ }^{3}$ \\ ${ }^{1}$ Laboratory of Advanced Materials, Faculty of Engineering, Hokkaido University, Sapporo 060-8628, Japan \\ ${ }^{2}$ Research Center for Physics, Indonesian Institute of Sciences (LIPI), Indonesia \\ ${ }^{3}$ Advanced Barrier-Coating Laboratory, Faculty of Engineering, Hokkaido University, Sapporo 060-8628, Japan
}

\begin{abstract}
An electron microscopy phase characterization was carried out for a Re-based diffusion barrier layer, which was deposited on the $\mathrm{Nb}$ substrate used as an ultra high temperature material. The coating process produced three layers; an outer $\mathrm{Cr}(\mathrm{Re})$ layer, an intermediate $\mathrm{Cr}-\mathrm{Nb}$ - $\mathrm{Re}$ layer, and an inner $\mathrm{Nb}(\mathrm{Re})$ layer. The $\mathrm{Cr}-\mathrm{Nb}$ - $\mathrm{Re}$ layer is considered to act as a diffusion barrier layer between the substrate and the outer $\mathrm{Cr}(\mathrm{Re})$ reservoir layer. $\mathrm{The} \mathrm{Cr}(\mathrm{Re})$ and $\mathrm{Nb}(\mathrm{Re})$ layers are in single phase with a similar bcc structures, but they are different in structure from the intermediate layer, which is composed of a dual phase of $\mathrm{Re}_{63} \mathrm{Cr}_{20} \mathrm{Nb}_{17}$ with a cubic structure and $\mathrm{Nb}_{42} \mathrm{Re}_{33} \mathrm{Cr}_{25} \mathrm{With}_{1}$ a hexagonal structure determined by transmission electron microscopy (TEM) in this study. [doi:10.2320/matertrans.MB201022]
\end{abstract}

(Received September 2, 2010; Accepted November 24, 2010; Published January 19, 2011)

Keywords: phase characterization, crystal structure, diffusion barrier layer, niobium, transmission electron microscopy

\section{Introduction}

Niobium has attracted attention as the basis for new materials for high temperature applications in place of $\mathrm{Ni}$ based superalloys. In order to increase the properties of $\mathrm{Nb}$ or $\mathrm{Nb}$-based alloys for applications that require the highest creep resistance, $\mathrm{Re}$ as one of the refractory metals has been selected for coating element. ${ }^{1,2)}$ Fundamental understanding of the crystal structure of the $\mathrm{Cr}-\mathrm{Nb}$-Re phase in the Re-based coating layer is important to control the coating process and to understand the mechanical properties of the coated layer. Moreover, the formation process of coatings with an Rebased diffusion barrier on $\mathrm{Nb}$-based alloys to improve the low oxidation resistance of these alloys was investigated by various methods in previous studies. ${ }^{3-5)}$ However, the crystal structure of the $\mathrm{Cr}-\mathrm{Nb}-\mathrm{Re}$ phases formed by the coating process has not been determined.

An obstacle in resolving this issue is that no $\mathrm{Cr}-\mathrm{Nb}-\mathrm{Re}$ ternary phase diagram has been established. It is well known that $\mathrm{Re}$ forms intermetallic compound phases by alloying with $\mathrm{Nb}$ or $\mathrm{Cr}$ : $\mathrm{Re}-\mathrm{Cr} \sigma$-phase, $\mathrm{Re}-\mathrm{Nb} \chi$-phase, and $\mathrm{Re}-\mathrm{Nb}$ $\sigma$-phase. ${ }^{6-8)}$ Nevertheless, estimates of the $\mathrm{Cr}-\mathrm{Nb}$-Re phase based only on the composition would be unreliable. Further, analysis by X-ray diffraction (XRD), which is the most general and conventional method for determining crystal structure of unknown phases, is also complicated in applying to the coating layer, because the coating layer has a multi-layer structure and usually has a thickness of about several $\mu \mathrm{m}$.

The objective of this study is to identify the crystal structure of the various phases in the $\mathrm{Cr}-\mathrm{Nb}$ - $\mathrm{Re}$ coating system by means of TEM. The paper will describe details of the selected area electron diffraction (SAED) patterns involving crystal structure and lattice constant analysis of the $\mathrm{Cr}-\mathrm{Nb}-\mathrm{Re}$ coating system. In the absence of other experimental data, this study will offer guidelines for developing Re-based diffusion barrier coatings on $\mathrm{Nb}$ or $\mathrm{Nb}$-based alloys.

*Corresponding author, E-mail: eni.sugiarti@eng.hokudai.ac.jp. Graduate Student, Hokkaido University

\section{Experimental}

A $99.99 \%$ Niobium ingot was cut into coupons of about $1 \mathrm{~mm}$ thickness. The specimen and it was polished to a $150-$ grit finish, then degreased in a methanol/benzene solution under ultrasonic agitation. A coating was developed involving electroplating of $\mathrm{Re}$ film from aqueous solution at temperature of $323 \mathrm{~K}$, followed by heat-treated in vacuum at $1723 \mathrm{~K}$ for $10.8 \mathrm{ks}$ to form a homogeneous Re film and pack cementation with $\mathrm{Cr}$ at $1673 \mathrm{~K}$ for $36 \mathrm{ks}$ in vacuum. Details of the formation process of the coating were presented elsewhere. $^{3)}$

The cross-section of the coated layer structure was first investigated by SEM. After the initial characterization, a cross-sectional TEM (XTEM) specimen, containing a diffusion barrier layer, was prepared by using an argon ion slicer (IS, JEOL EIS 9100) to ensure the minimum structural damage. The sample had to be cut in a size to $2.8 \times 0.45 \times$ $0.1 \mathrm{~mm}$ prior to the IS, causing spallation of the outer layer due to the weak bonding of the coated layer during cutting and polishing. Additionally, a focused ion beam (FIB, JFIB 2300) technique was used to obtain XTEM specimens at specific sites, which is not possible by the IS method. With these two methods, it is possible to prepare XTEM specimens which yield good results. The TEM observations were performed using a JEOL JEM $2010 \mathrm{~F}$ at $200 \mathrm{kV}$ equipped with an energy dispersive X-ray spectroscope (EDS).

\section{Results and Discussion}

\subsection{Coating-layer structure and composition}

The cross-sectional structure of an as-coated specimen is shown in Fig. 1(a). It was found from a SEM image in Fig. 1(a) and a EDS result in Fig. 1(b) that the coating comprises three-layers: the first layer of $\mathrm{Cr}(\mathrm{Re})$, the second layer of $\mathrm{Cr}-\mathrm{Nb}-\mathrm{Re}$, the third layer of $\mathrm{Nb}(\mathrm{Re})$, and then there is the $\mathrm{Nb}$ substrate. The EDS result (Fig. 1(b)), which was performed along the line in (a), indicates that the outer $\mathrm{Cr}(\mathrm{Re})$ layer contains $(100-78$ at\%) $\mathrm{Cr}$ and $(22-1$ at $\%) \mathrm{Re}$, the intermediate $\mathrm{Cr}-\mathrm{Nb}$-Re layer contains (60-22 at\%) Re, (45- 

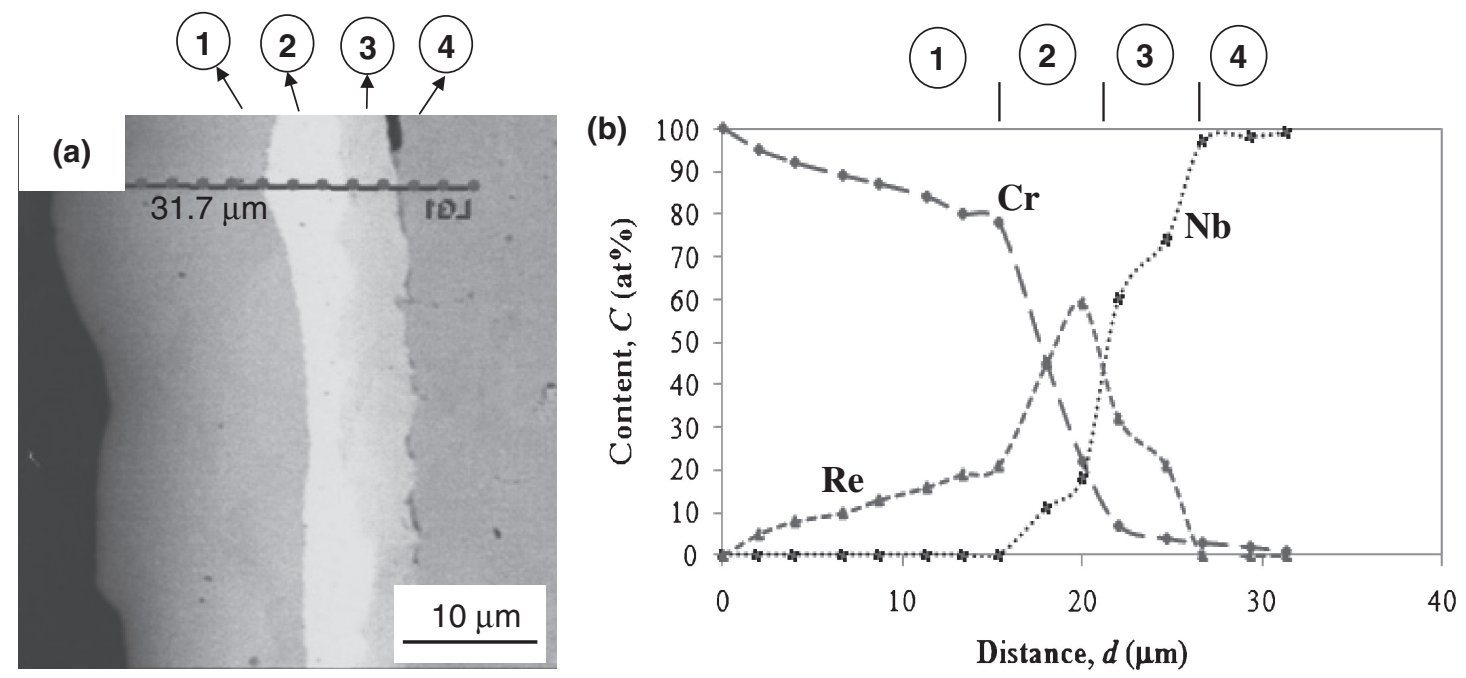

Fig. 1 (a) Cross-sectional SEM image and (b) concentration profiles for three layers after Re plating followed by Cr-pack cementation on $\mathrm{Nb}$ substrate at $1673 \mathrm{~K}$ for $36 \mathrm{ks}$. (1) outer $\mathrm{Cr}(\mathrm{Re})$, (2) intermediate $\mathrm{Cr}-\mathrm{Nb}-\mathrm{Re}$, (3) inner $\mathrm{Nb}(\mathrm{Re})$, and (4) $\mathrm{Nb}$ substrate.

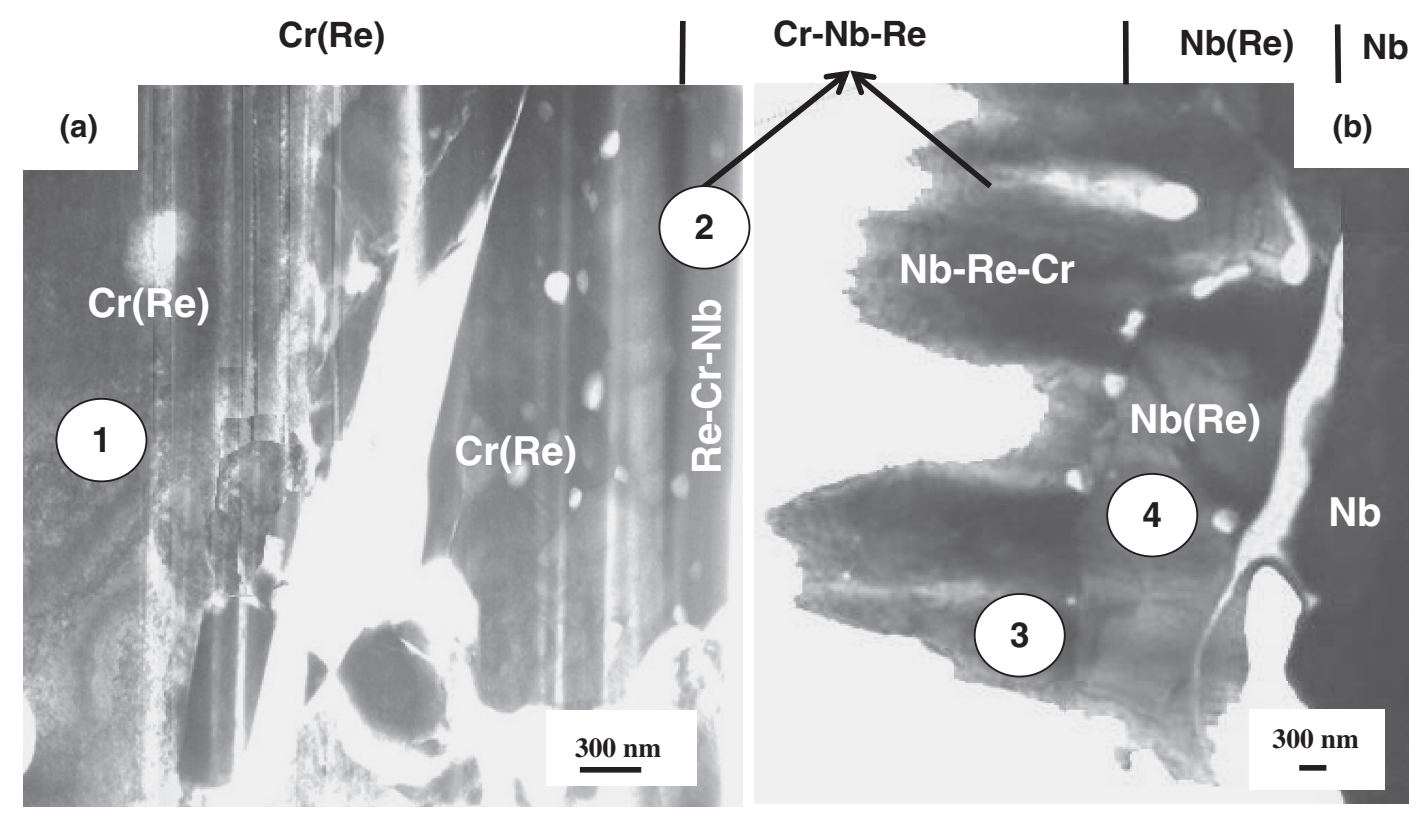

Fig. 2 Bright field XTEM images of the Cr-Nb-Re system (a) two layers at the top which are $\mathrm{Cr}_{75} \mathrm{Re}_{24}$ and $\mathrm{Re}_{63} \mathrm{Cr}_{20} \mathrm{Nb}_{17}$ and (b) three layers at the bottom which are $\mathrm{Nb}_{42} \mathrm{Re}_{33} \mathrm{Cr}_{25}, \mathrm{Nb}_{70} \mathrm{Re}_{27}$ and $\mathrm{Nb}$ substrate. There are cracks in the $\mathrm{Cr}(\mathrm{Re}) \operatorname{layer}$ and on the $\mathrm{Nb}(\mathrm{Re})-\mathrm{Nb}$ interface. Cavities are formed mainly in the $\mathrm{Cr}-\mathrm{Nb}-\mathrm{Re}$ layer.

$24 \mathrm{at} \%) \mathrm{Cr}$ and $(18-12 \mathrm{at} \%) \mathrm{Nb}$, and the inner $\mathrm{Nb}(\mathrm{Re})$ layer contains $(98-60$ at $\%) \mathrm{Nb},(33-20$ at $\%) \mathrm{Re}$ and $(6-3$ at $\%) \mathrm{Cr}$. It was confirmed that the intermediate $\mathrm{Cr}-\mathrm{Nb}$-Re layer formed homogeneously (Fig. 1(a)) and the concentrations of $\mathrm{Cr}, \mathrm{Nb}$ and Re varied sharply at the interfaces (Fig. 1(b)).

XTEM images of the coating layer are shown in Fig. 2(a) and (b) obtained from FIB and IS specimens, respectively. Table 1 shows the results of the EDS analysis obtained from the circled area in Fig. 2. In agreement with the results in Fig. 1, the layer-structure, from the surface, consists of an outer $\mathrm{Cr}(\mathrm{Re})$ layer with a thickness of about $15 \mu \mathrm{m}$, an intermediate $\mathrm{Cr}-\mathrm{Nb}-\mathrm{Re}$ layer of about $6 \mu \mathrm{m}$, and an inner $\mathrm{Nb}(\mathrm{Re})$ layer of about $6 \mu \mathrm{m}$. The roughness of the $\mathrm{Cr}-\mathrm{Nb}-\mathrm{Re}$ surface in Fig. 2(b) is a local artifact and probably caused by the IS process. In addition, there are many defects, cracks,
Table 1 Composition determined from the circled area of the coated layers (EDS analysis in TEM).

\begin{tabular}{|c|c|c|c|}
\hline \multirow{2}{*}{ Layer } & \multicolumn{3}{|c|}{ Element (at\%) } \\
\hline & $\mathbf{N b}$ & $\mathbf{R e}$ & $\mathrm{Cr}$ \\
\hline $\begin{array}{c}\mathrm{Cr}(\mathrm{Re}) \\
\text { (area } 1 \text { in Fig. 2(a)) }\end{array}$ & 1 & 24 & 75 \\
\hline $\begin{array}{c}\mathrm{Re}-\mathrm{Cr}-\mathrm{Nb} \\
\text { (area } 2 \text { in Fig. 2(a)) }\end{array}$ & 17 & 63 & 20 \\
\hline $\begin{array}{c}\mathrm{Nb}-\mathrm{Re}-\mathrm{Cr} \\
\text { (area } 3 \text { in Fig. 2(b)) }\end{array}$ & 42 & 33 & 25 \\
\hline $\begin{array}{c}\mathrm{Nb}(\mathrm{Re}) \\
\text { (area } 4 \text { in Fig. 2(b)) }\end{array}$ & 70 & 27 & 3 \\
\hline
\end{tabular}



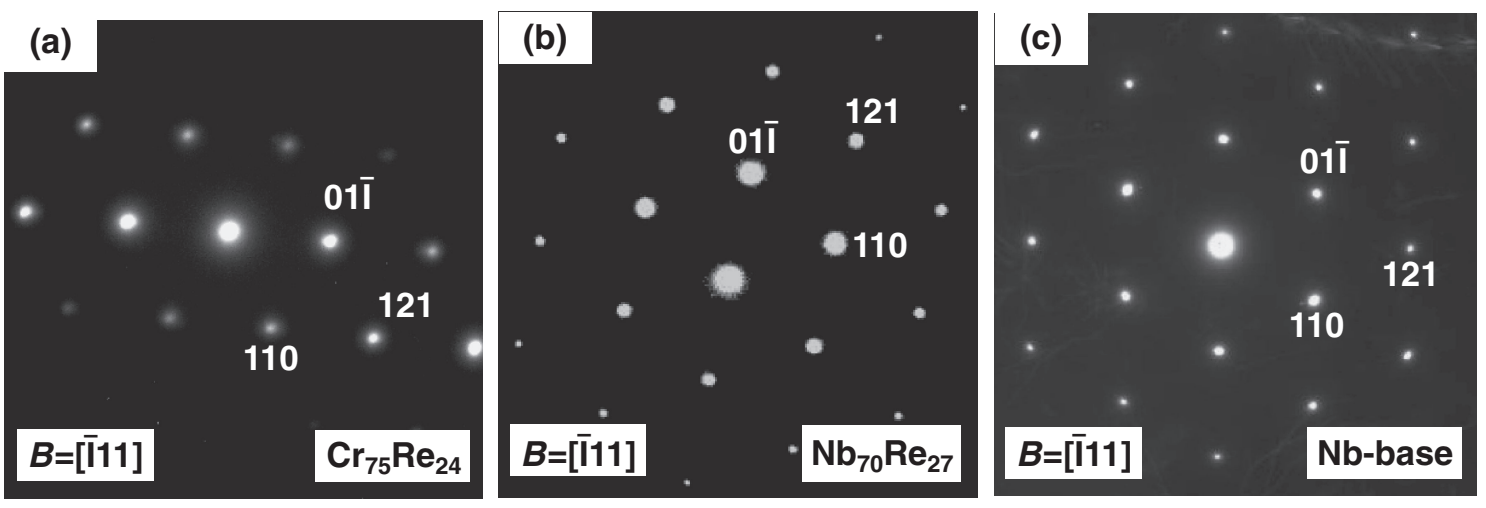

Fig. 3 SAED patterns showing a bcc structure of (a) $\mathrm{Cr}_{75} \mathrm{Re}_{24}$, (b) $\mathrm{Nb}_{70} \mathrm{Re}_{27}$, and (c) $\mathrm{Nb}$ substrate layers.

and pores in the interface between $\mathrm{Cr}(\mathrm{Re}), \mathrm{Cr}-\mathrm{Nb}-\mathrm{Re}$ and $\mathrm{Nb}(\mathrm{Re})$ layers, influencing the durability of the coating system.

The Re-riched intermediate $\mathrm{Cr}-\mathrm{Nb}$-Re layer is considered to act as a diffusion barrier between the substrate and an additional outer reservoir layer for both inward and outward diffusion, and the phases here are directly related to the stability and durability of the coating. Therefore, understanding the phases, especially the $\mathrm{Cr}-\mathrm{Nb}-\mathrm{Re}$ phase, in the coating system is critical for the design of the Re-based diffusion barrier layer on the $\mathrm{Nb}$ or $\mathrm{Nb}$-based alloy substrate. However, the phase of the $\mathrm{Cr}-\mathrm{Nb}-\mathrm{Re}$ compounds cannot be determined only from the EDS results because of the reason as mentioned earlier. The phase identification using electron diffraction method was carried out in this study.

\subsection{Phase identification of the coating layer}

It is possible to determine the crystal structures of the outer-layer $\mathrm{Cr}(\mathrm{Re})$ and inner layer $\mathrm{Nb}(\mathrm{Re})$ phases, because the phases were almost composed of only the two elements and the binary phase diagrams for these elements can be applied. The binary phase diagrams suggest the phases to be solid solutions with similar crystal structures, a body-centercubic (bcc) structure, and verification of this was performed using SAED as shown in Fig. 3. The lattice constants determined from the patterns are shown in Table 2, and the results are in accord with the lattice constants of $\mathrm{Cr}_{70} \mathrm{Re}_{30}$ and $\mathrm{Nb}_{60} \mathrm{Re}_{40}$ phases in the Powder X-ray database. ${ }^{6)}$ Because the atomic radiuses of $\mathrm{Cr}, \mathrm{Re}$, and $\mathrm{Nb}$ in the crystals are different: $\mathrm{Cr}(0.125 \mathrm{~nm})<\operatorname{Re}(0.137 \mathrm{~nm})<\mathrm{Nb}(0.143 \mathrm{~nm})$, the lattice constant of the $\mathrm{Cr}(\mathrm{Re})$ phase is slightly larger than that of pure $\mathrm{Cr}$, the lattice constant of the $\mathrm{Nb}(\mathrm{Re})$ phase is slightly smaller than that of $\mathrm{Nb}$. With the data in Ref. 6) and the atomic radiuses, the differences in the lattice constants compared with pure $\mathrm{Cr}$ and $\mathrm{Nb}$ phases can be calculated to represent a $2.5 \%$ expansion for the $\mathrm{Cr}(\mathrm{Re})$ phase and a $1.2 \%$ shrinkage for the $\mathrm{Nb}(\mathrm{Re})$ phase, in good agreement with the experimental results.

For the phase of the $\mathrm{Cr}-\mathrm{Nb}-\mathrm{Re}$ layer, as previously mentioned, it is difficult to determine the crystal structure only by the composition, because of the absence of a ternary phase diagram based on experiments. Similar to the $\sigma$-phase formed in Ni-based alloys, an intermetallic compound phase was suggested to be formed on the $\mathrm{Nb}$ substrate in this study.
Table 2 Unit cell parameters determined from the coated layers.

\begin{tabular}{cccc}
\hline \multirow{2}{*}{ Layer } & \multirow{2}{*}{ Crystal structure } & \multicolumn{2}{c}{ Unit Cell Parameter (nm) } \\
\cline { 3 - 4 } & & a & c \\
\hline $\mathrm{Cr}_{75} \mathrm{Re}_{24}$ & bcc & 0.297 & - \\
$\mathrm{Re}_{63} \mathrm{Cr}_{20} \mathrm{Nb}_{17}$ & Cubic & 0.953 & \\
$\mathrm{Nb}_{42} \mathrm{Re}_{33} \mathrm{Cr}_{25}$ & Hexagonal & 0.512 & 0.823 \\
$\mathrm{Nb}_{70} \mathrm{Re}_{27}$ & bcc & 0.322 & - \\
$\mathrm{Nb}$-substrate & bcc & 0.328 & - \\
\hline
\end{tabular}

According to the $\mathrm{Cr}-\mathrm{Re}, \mathrm{Cr}-\mathrm{Nb}$, and $\mathrm{Nb}-\mathrm{Re}$ binary diagrams, $\mathrm{Cr}-\mathrm{Re} \sigma$ phase, $\mathrm{Cr}_{2} \mathrm{Nb} \alpha$ phase, $\mathrm{Cr}_{2} \mathrm{Nb} \beta$ phase, $\mathrm{Nb}-\mathrm{Re} \sigma$ phase, and $\mathrm{Nb}$-Re $\chi$ phase are possibly formed as a $\mathrm{Cr}-\mathrm{Nb}-\mathrm{Re}$ phase. ${ }^{8)}$ In the case of limited experimental phase equilibrium data, electron diffraction is an option for determining the crystal structure of a new phase. ${ }^{9)}$ From this reasoning, the crystal structure of the $\mathrm{Cr}-\mathrm{Nb}-\mathrm{Re}$ phase was determined by using SAED. In the area as shown in Fig. 2, the Cr-Nb-Re layer is formed by a dual phase, suggested as the EDS results indicate different compositions in the layer from the top and bottom sides. Therefore, to improve the accuracy and reliability of the dual phase identification for the $\mathrm{Cr}-\mathrm{Nb}-\mathrm{Re}$ layer, several SAED patterns were obtained from the same crystal grain in each phase by tilting the specimen (shown by the $B$ value in the Fig. 4 and 5).

All of the SAED patterns correspond well to cubic and hexagonal structures rather than cubic $\left(\alpha-\mathrm{Cr}_{2} \mathrm{Nb}\right.$ phase) or tetragonal ( $\mathrm{Cr}-\mathrm{Re}$ or $\mathrm{Nb}-\mathrm{Re} \sigma$ phase) structures. To determine the crystal structure of the first phase of the $\mathrm{Cr}-\mathrm{Nb}$-Re layer, Ref. 7) shows that cubic $\mathrm{NbRe}_{2}$ and $\mathrm{Nb}_{37} \mathrm{Re}_{63}-\chi$ phases have a lattice contant of $a=0.9670 \mathrm{~nm}$ and $a=0.9675 \mathrm{~nm}$, respectively. Therefore, the $\mathrm{Re}_{63} \mathrm{Cr}_{20} \mathrm{Nb}_{17}$ phase can be identified as $\chi$ phase due to the lattice constant calculated from the SAED patterns in Fig. 4 with $a=0.953 \mathrm{~nm}$ which is smaller than the value in Ref. 7) and probably influenced by the $\mathrm{Cr}$ constituent in the compound here. The second phase of the $\mathrm{Cr}-\mathrm{Nb}-\mathrm{Re}$ layer can be determined by comparing the lattice constants and the structure of the $\beta-\mathrm{Cr}_{2} \mathrm{Nb}$ phase appears as the likely candidate. The $\beta-\mathrm{Cr}_{2} \mathrm{Nb}$ phase is isostructural to a $\mathrm{MgZn}_{2}$ type laves phase with 12 atoms per unit cell, and the lattice constants are $a=0.4976 \mathrm{~nm}$ and $\left.c=0.8059 \mathrm{~nm} .{ }^{6}\right)$ According to the SAED patterns in Fig. 5, the lattice constant calculations of the $\mathrm{Nb}_{42} \mathrm{Re}_{33} \mathrm{Cr}_{25}$ phase 

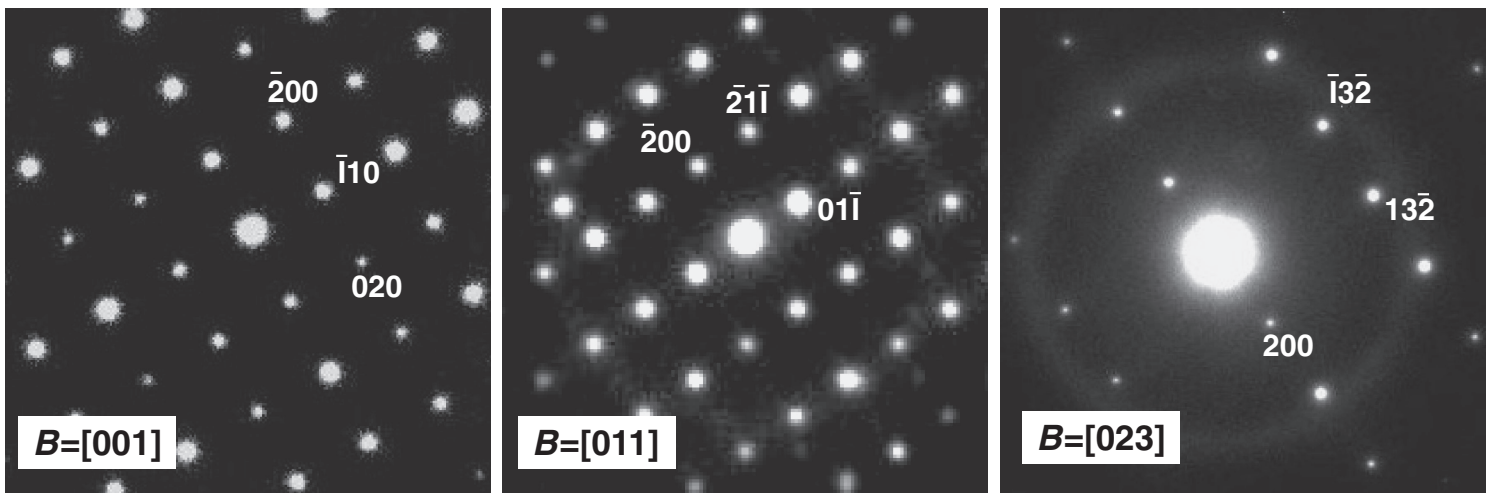

Fig. 4 SAED patterns showing a cubic crystal structure of a $\operatorname{Re}_{63} \mathrm{Cr}_{20} \mathrm{Nb}_{17} \chi$ phase.
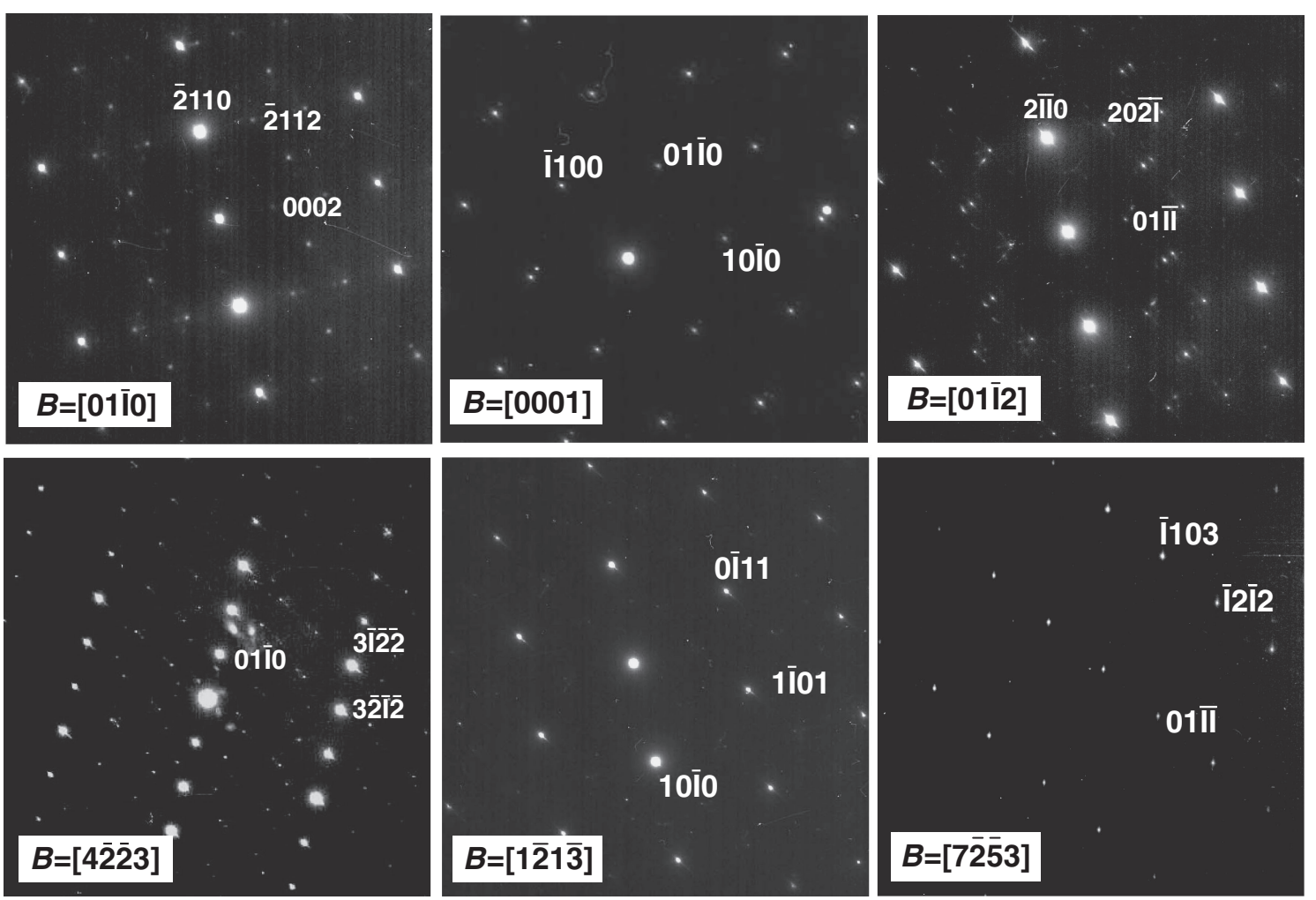

Fig. 5 SAED patterns showing a hexagonal crystal structure of a $\mathrm{Nb}_{42} \mathrm{Re}_{33} \mathrm{Cr}_{25}$ layer.

are $a=0.512 \mathrm{~nm}$ and $c=0.823 \mathrm{~nm}$, which are somewhat larger than those in $\beta-\mathrm{Cr}_{2} \mathrm{Nb}$ phases. It should be noted that a $\beta-\mathrm{Cr}_{2} \mathrm{Nb}$ phase is a high temperature equilibrium phase formed only at temperatures above $1873 \mathrm{~K}$, but an isostructural $\mathrm{Nb}_{42} \mathrm{Re}_{33} \mathrm{Cr}_{25}$ phase forms at a relatively lower temperature of $1673 \mathrm{~K}$ due to the the $\mathrm{Re}$ constituent in this compound. It must be mentioned that only the cubic $\chi$ phase and a hexagonal structure could be determined in the XTEM specimens here. We were unable to find any of the $\sigma$ phase that has been reported to act as a diffusion barrier in Ni-based alloys.

\section{Conclusions}

This investigation reports a cross-sectional TEM analysis performed to identify the crystalline structure and composition of an Re-based diffusion barrier layer on an $\mathrm{Nb}$ substrate, which consists of an outer $\mathrm{Cr}_{75} \mathrm{Re}_{24}$ layer with a thickness of about $15 \mu \mathrm{m}$, an intermediate $\mathrm{Cr}-\mathrm{Nb}-\mathrm{Re}$ layer of about $6 \mu \mathrm{m}$, and an inner $\mathrm{Nb}_{70} \mathrm{Re}_{27}$ layer of about $6 \mu \mathrm{m}$. A crystal structure of $\mathrm{Cr}_{75} \mathrm{Re}_{24}$ and $\mathrm{Nb}_{70} \mathrm{Re}_{27}$ layers were determined by combining the phase descriptions of the three sub-binary systems and it was verified by lattice constant calculations from the SAED patterns, showing the same crystal structure, a bcc structure. For the phase of the $\mathrm{Cr}-\mathrm{Nb}$-Re layer, there are a number of phases which could be formed in accord with the sub-binary diagrams, $\mathrm{Cr}-\mathrm{Re} \sigma$ phase, $\mathrm{Cr}_{2} \mathrm{Nb} \alpha$ phase, $\mathrm{Cr}_{2} \mathrm{Nb}$ $\beta$ phase, $\mathrm{Nb}-\mathrm{Re} \sigma$ phase, and $\mathrm{Nb}-\mathrm{Re} \chi$ phase. Several SAED patterns were confirmed from the same crystal grain of the $\mathrm{Cr}-\mathrm{Nb}$-Re layer and suggested a dual phase with cubic $\chi$ phase and a hexagonal structure. Overall, the results of the calculations of the $\mathrm{Cr}-\mathrm{Nb}-\mathrm{Re}$ lattice constants suggest a $\mathrm{Re}_{63} \mathrm{Cr}_{20} \mathrm{Nb}_{17}$ with cubic $\chi$ phase of $a=0.953 \mathrm{~nm}$ and a $\mathrm{Nb}_{42} \mathrm{Re}_{33} \mathrm{Cr}_{25}$ with hexagonal structure of $a=0.512 \mathrm{~nm}$ and 
$c=0.823 \mathrm{~nm}$. In the absence of experimental data, the results here provide a guideline and will be useful for improving the performance of an Re-based diffusion barrier layers on $\mathrm{Nb}$ and $\mathrm{Nb}$-based substrates, something that is necessary before these coated layer systems can be considered for service or commercial alloys.

\section{Acknowledgments}

The author wish to thank all colleagues involved in the project for their help and input especially to all of staff in the advanced barrier-coating laboratory for providing the coating samples. One of the authors will express her gratitude to Inpex Foundation with grants for scholarships. This work was supported by Japan Aerospace Exploration Agency (JAXA) of Japan.

\section{REFERENCES}

1) R. C. Reed: The Superalloy: Fundamentals and Applications, (Cambridge University Press, 2006).

2) T. Jin, W. Wang, X. Sun and Z. Hu: Mater. Sci. Forum 638-642 (2010) 2257-2262.

3) K. Saito, S. Hayashi, T. Narita, I. Iwanaga and R. Tanaka: Mater. Sci. Forum 522-523 (2006) 309-316.

4) Y. Matsumura, M. Fukumoto, S. Hayashi, A. Kasama, I. Iwanaga, R. Tanaka and T. Narita: Oxid. Metals 61 (2004) 105-124.

5) M. Fukumoto, Y. Matsumura, S. Hayashi, K. Sakamoto, A. Kasama, R. Tanaka and T. Narita: Oxid. Metals 60 (2003) 335-346.

6) J. M. Joubert: Progr. Mater. Sci. 53 (2008) 528-583.

7) J. M. Joubert and M. Phejar: Progr. Mater. Sci. 54 (2009) 945-980.

8) T. B. Massalski: Binary Alloy Phase Diagram, 2nd ed., (ASM International, 1990).

9) L. A. Bendersky and F. W. Gayle: J. Res. Natl. Inst. Stand. Technol. 106 (2001) 997-1012. 